\title{
“Globesization": Ecological Evidence On The Relationship Between Fast Food Outlets and Obesity Among 26 Advanced Economies
}

Roberto De Vogli1 2, PhD, MPH, Anne Kouvonen ${ }^{3}, P h D$, David Gimeno 4 , PhD

${ }^{1}$ Department of Health Behaviors and Health Education, School of Public Health, University of Michigan, Ann Arbor, US.

${ }^{2}$ International Institute for Society and Health, Department of Epidemiology and Public Health, University College London, London, UK.

${ }^{3}$ Warsaw School of Social Sciences and Humanities, Wroclaw Faculty, Poland.

${ }^{4}$ Division of Epidemiology, Human Genetics and Environmental Health Sciences, San Antonio Campus of the School of Public Health, The University of Texas Health Science Center at Houston, US

\author{
Abstract text: 245 \\ Words text: 1,886 \\ Tables: 1 \\ Figures: 1 \\ References: 24
}

Correspondence to: Roberto De Vogli, Department of Health Behavior and Health Education, School of Public Health, University of Michigan, 1415 Washington Heights, Ann Arbor, MI 48109-2029 (US) (email: rdevogli@umich.edu). 


\begin{abstract}
The aim of this study was to investigate the relationship between the density of fast food restaurants and the prevalence of obesity by gender across affluent nations. Data on Subway's restaurants per 100,000 people and proportions of men and women aged 15 years or older with a body mass index (BMI) higher or equal than $30 \mathrm{Kg} / \mathrm{m}^{2}$ were obtained for 26 of 34 advanced economies. Countries with the highest density of Subway restaurants such as the US (7.52 per 100,000) and Canada (7.43 per 100,000) tend also to have a higher prevalence of obesity in both men (31.3\% and $23.2 \%$ respectively) and women (33.2\% and $22.9 \%$ respectively). On the other hand, countries with a relatively low density of Subway restaurants such as Japan $(0.13$ per 100,000$)$ and Norway $(0.19$ per 100,000$)$ had a lower prevalence of obesity in both men $(2.9 \%$ and $6.4 \%$ respectively) and women $(3.3 \%$ and $5.9 \%$ respectively). Unadjusted linear regression models showed a significant correlation between the density of Subway's outlets and the prevalence of adult obesity ( $\beta=.46 ; p=0.02$ in men and $\beta=.48 ; p=0.013$ in women). When the data were weighted by population size, the association became substantially stronger in both men and women $(\beta=.85 ; p=0.0001$ and $\beta=.84 ; p=0.0001$, respectively). Covariate adjustment did not reduce the size of the associations. Our study raises serious concerns about that the diffusion of fast food outlets worldwide and calls for coordinated political actions to address what we term 'globesization', the ongoing globalization of the obesity epidemic.
\end{abstract}

Keywords: Fast Food, Globalization, Obesity, Transnational Corporations, Wealthy Nations, Trade Liberalization, World Trade Organization. 


\section{Introduction}

Over the past 30 years the prevalence of obesity has substantially increased in high-income countries (Yach, Stuckler, and Brownell 2006). The diffusion of "fast food restaurants" resulting from rapid global market integration (Hawkes 2009) and trade liberalization policies (Thow and Hawkes 2009) seems to be one of the key contributing factors behind the sharp rise of obesity. Trade liberalization policies, in particular, have contributed to increase both exports of domestic goods and imports of foreign products and the opening of national markets to foreign investment. These reforms, strongly promoted by international financial institutions such as the World Trade Organization (WTO) (Rayner et al. 2007) have been, and still are, particularly instrumental in promoting the growth and power of transnational food companies (TFCs) (Hawkes 2009). The rising dominance and economic power of TFCs, the global spread of supermarkets and fast food companies such as McDonald's and Subway have produced dramatic changes in people's dietary patterns. A study by Bowman and colleagues, for example, estimated that, in the US, almost one third of young people now eat at a fast food restaurant on any given day (Bowman et al. 2004). This can further increase the prevalence of obese and overweight adults in the future. A number of studies have, in fact, shown that consumption of items frequently sold in "fast food" restaurants such as hamburgers and French fries is positively related with body weight (French, Harnack, and Jeffrey 2000; Jeffrey and French 1998; Prentice and Jebb 2003).

Although a growing number of studies have examined the association between the availability of fast food outlets and obesity (Fraser et al. 2010), only a few of them have analyzed the cross-national correlates of obesity (Offer, Pechey, and Ulijaszek 2010; Rabin, Boehmer, and Brownson 2007). In this article, we examined the association between the density of Subway's restaurants and the prevalence of obesity in men and women in 26 advanced economies. Subway is expected to overtake McDonald's as the world's largest fast-food chain in terms of outlets (Business-Week 2009).

\section{Methods}

\section{Design and data sources}

In order to study the relationship between the density of Subway's restaurants and the prevalence of obesity by gender in advanced economies, we conducted an ecological, cross-national study of countries with available data on both measures. Of the 34 advanced economies identified according to the International Monetary Fund (IMF) criteria (IMF 2009), data on obesity prevalence for men and women and on Subway restaurants were available for 26 countries. Data on the major dependent variable, obesity prevalence by gender (proportion of men and women aged $\geq 15$ years with body mass index (BMI) $\geq 30 \mathrm{Kg} / \mathrm{m}^{2}$ ), were taken from the World Health Statistics, 2009 (WHO 2009). The number of Subway's restaurants for each country was obtained from the Subway (Subway) website as of December 2009. Population data for each advanced nation were used to calculate 
density measures of Subway's restaurants per 100,000 people. This measure was then transformed into a natural log indicator.

Covariates included a list of potential confounding factors that could explain the association between the density of fast food outlets and the prevalence of obesity. They included gross national income (GNI) per capita, proportion of people living in urban areas, the Gini coefficient, motor vehicles and internet users. Data on gross national income per capita (converted to international dollars \$ using purchasing power parities PPP), proportion of people living in urban areas, motor vehicles per 1,000 people and internet users per 100 people were taken from the World Development Indicators database published in 2009. Data on population size come from the Central Intelligence Agency (CIA) World Factbook, 2009. Data on income inequality, measured by the Gini coefficient, were taken from the United Nations Development Program's Human Development Indicators published in 2009.

\section{Statistical Analyses}

Unadjusted associations between the density of Subway restaurants and the prevalence of obesity separately for men and women were examined by simple linear regression models. Results of simple linear regression models are presented weighted and unweighted for population size. Multivariate linear regressions were used to calculate the standardized beta-coefficients (which equal the correlation coefficients, $r$ ) of the cross-national associations between Subway's restaurants per 100,000 people and the prevalence of obesity by gender controlling for covariates. A major concern for these multivariate analyses was the degree of multicollinearity between highly correlated predictors that could potentially result in unstable coefficients and standard errors. As an indicator of multicollinearity, we used variance inflation factor (VIF) values greater than or equal to 10 (Belsley 1991). First, the associations of interest were adjusted for GNI per capita, urbanization and the Gini Coefficient. A second model, where covariates also included motor vehicles per 1,000 people and internet users per 100 people, presented problems of multicollinearity (VIF values for GNI per capita, the Gini coefficient and internet users were higher than 10). We therefore decided to drop the Gini coefficient from the model. Robust standard errors, the so-called "sandwich estimators", were used to account for violations of the normality assumption in linear regressions (Baum 2006) Statistical analyses were conducted using Stata 11.0 software (StataCorp LP, College Station, TX).

\section{Results}

The results showed that there is a large variation in both the density of Subway's restaurants and the prevalence of obesity across the selected countries (Table 1). Countries with the highest density of Subway restaurants such as the US (7.52 per 100,000) and Canada $(7.43$ per 100,000) tend also to have a higher prevalence of obesity in both men $(31.3 \%$ and $23.2 \%$ respectively) and women (33.2\% and $22.9 \%$ respectively). On the other hand, countries with a relatively low density of Subway restaurants such as Japan $(0.13$ per 100,000$)$ and Norway $(0.19$ 
per 100,000$)$ have a lower prevalence of obesity in both men $(2.9 \%$ and $6.4 \%$ respectively) and women ( $3.3 \%$ and $5.9 \%$ respectively).

Scatterplots of data on the density of Subway's outlets and the prevalence of obesity in men and women across the 26 advanced economies are presented in Figures $1 \mathrm{~A}$ and 1B. Simple linear regression models showed that the density of Subway's outlets per 100,000 was significantly correlated with the prevalence of adult obesity in both genders $(\beta=.46 ; p=0.02$ in men and $\beta=.48 ; p=0.01$ in women). When the data were weighted by population size, the associations became substantially stronger in both men and women $(\beta=.85 ; p=0.0001$ and $\beta=.84$; $\mathrm{p}=0.0001$, respectively). After adjustment for GNI per capita, urbanization and the Gini coefficient, the size of the associations remained strongly significant in both men $(\beta=.61 ; p=0.001)$ and women $(\beta=.57 ; p=0.001$.) After additional adjustment for motor vehicles per 1,000 people and internet users per 100 people (excluding the Gini coefficient from the model to avoid problems of multicollinearity), the associations still remained significant $(\beta=.72 ; p=0.005$ and $\beta=.68 ; p=0.002)$.

\section{Conclusions}

The relationship between the density of fast food restaurants and the prevalence of obesity has received increasing attention in the literature. Several studies have shown that a higher density of fast food restaurants can be an environmental promoter of obesity (French et al. 2000; Jeffrey and French 1998; Prentice and Jebb 2003). Our findings indicate that the density of Subway's outlets is positively associated with the prevalence of obesity across 26 advanced economies in both men and women. These relationships remained significant after adjustment for GNI per capita, proportion of people living in urban areas and income inequality. They also remained significant in a model that included additional covariates such as motor vehicles per capita and internet users per capita.

Our results must be interpreted with caution. Given the cross-sectional study design we cannot infer causality between the density of fast food restaurants and the prevalence of obesity. Also, the cross-sectional nature of our exploratory study does not take into account the potential time lag between exposure to fast food restaurants and the increase of obesity prevalence. Furthermore, our measure of the density of fast food outlets was restricted to only one fast food chain. Finally, although it is plausible to expect our findings to be relevant for middle- and lowincome countries experiencing the "nutrition transition" as well, our analysis were limited to adult populations of 26 advanced economies only. Data were not available for 8 of the IMF advanced countries including large economies such as South Korea, Taiwan and Hong Kong: their exclusion may have influenced our results.

In spite of these shortcomings, our study provides novel findings of the ecological association between the availability of fast food and the prevalence of obesity in advanced economies. Our findings are consistent with aggregate level studies showing associations between fast food restaurants and obesity prevalence (Block, Scribner, and DeSalvo 2004; Cummins, McKay, and McIntyre 2005; Maddock 2004 ; Reidpath et al. 2002). An investigation of 50 US states showed that both the number of residents per fast food restaurant and the square miles per fast food 
restaurants were significantly associated with state-level obesity prevalence (Maddock 2004 ). In addition, a recent study showed that countries with market liberal welfare regimes (which are also English speaking) have a higher prevalence of obesity and easier access to fast food (e.g. a lower Big Mac relative price) (Offer et al. 2010) than countries with different welfare regimes.

However, our results are inconsistent with findings at the individual level (Burdesse and Whitaker 2004) (Jeffrey et al. 2006) showing no associations between proximity to fast food restaurants and obesity after adjustment for other factors. Some of these studies were affected by a number of shortcomings. One was restricted to low income children under the age of 5 years (Burdesse and Whitaker 2004). Another relied on self-reported measures of body height and weight and the frequency of eating at restaurants derived from a telephone survey (Jeffrey et al. 2006) that can be affected by self-report biases especially among low income groups. This is serious because evidence shows that people of low income are also more likely to be obese (Cummins et al. 2005). In a recent article, Fraser and colleagues argued that their review of studies investigating the relationship between availability to fast food outlets and overweight/obesity generated "conflicting results." The authors also specified that findings on the ecological associations between the density of fast food outlets and the prevalence of obesity "have, largely, not been verified with the results from studies using individual level data" (Fraser et al. 2010). It is important to highlight, however, that the aim of ecological level analyses such as the one presented in this article is not to explain individual differences in obesity and increased access to fast food outlets, but societal level variations in environmental factors associated to obesity. The aim of aggregate level studies on the structural correlates of obesity is not to apply ecological level results to individuals and falling into the problem of "ecological fallacy," (Pearce 2000) but to exclusively focus on policy-relevant, societal level determinants of health outcomes. Nevertheless, future policy-oriented research should investigate changes over time in obesity prevalence and the diffusion of fast food restaurants and trade liberalization policies across countries.

Finally, although our results are preliminary and exploratory, they suggest that the diffusion of fast food outlets, and trade liberalization policies promoting their growth and expansion worldwide, may contribute to the obesity epidemic. Our study also raises serious issues about the role of international financial institutions such as the World Trade Organization (WTO) in promoting free trade and food market integration and calls for coordinated political actions to address what we term 'globesization', the ongoing globalization of the obesity epidemic. 
Table 1 The prevalence of obesity in men and women, the number of Subway restaurants per 100,000 and Population Size in 26 Advanced Economies, 2009

\begin{tabular}{|c|c|c|c|c|}
\hline \multirow[t]{2}{*}{ Country } & $\%$ of & $\begin{array}{l}15 \text { years of age } \\
\text { obese }\end{array}$ & \multirow{2}{*}{$\begin{array}{l}\text { Subway } \\
\text { restaurants } \\
\text { per } 100,000\end{array}$} & \multirow{2}{*}{$\begin{array}{l}\text { Population } \\
\text { size - in } \\
\text { millions }\end{array}$} \\
\hline & Men & Women & & \\
\hline
\end{tabular}

\begin{tabular}{|c|c|c|c|c|}
\hline Australia & 20.6 & 25.5 & 5.65 & 21.0 \\
\hline Austria & 13.0 & 9.0 & 0.07 & 8.3 \\
\hline Belgium & 11.9 & 13.4 & 0.15 & 10.4 \\
\hline Canada & 22.9 & 23.2 & 7.43 & 33.2 \\
\hline Czech Rep. & 13.7 & 16.3 & 0.12 & 10.2 \\
\hline Denmark & 11.8 & 11.0 & 0.07 & 5.4 \\
\hline Finland & 16.0 & 14.0 & 1.39 & 5.2 \\
\hline France & 16.1 & 17.6 & 0.28 & 61.0 \\
\hline Germany & 20.5 & 21.1 & 0.96 & 82.3 \\
\hline Greece & 26.0 & 18.2 & 0.05 & 10.7 \\
\hline Iceland & 12.4 & 12.3 & 5.91 & 0.3 \\
\hline Ireland & 14.0 & 12.0 & 2.62 & 4.1 \\
\hline Israel & 19.8 & 25.4 & 0.11 & 7.1 \\
\hline Italy & 7.4 & 8.9 & 0.01 & 58.1 \\
\hline Japan & 2.9 & 3.3 & 0.13 & 127.2 \\
\hline Netherlands & 10.2 & 11.9 & 0.46 & 16.6 \\
\hline New Zealand & 21.9 & 23.2 & 5.10 & 4.1 \\
\hline Norway & 6.4 & 5.9 & 0.19 & 4.6 \\
\hline Portugal & 15.0 & 13.4 & 0.01 & 10.6 \\
\hline Singapore & 6.4 & 7.3 & 1.62 & 4.6 \\
\hline Slovakia & 13.5 & 15.0 & 0.07 & 5.4 \\
\hline Spain & 13.0 & 13.5 & 0.06 & 40.4 \\
\hline Sweden & 11.0 & 14.0 & 0.69 & 9.0 \\
\hline Switzerland & 7.9 & 7.5 & 0.05 & 7.5 \\
\hline United Kingdom & 22.3 & 23.0 & 2.23 & 60.9 \\
\hline USA & 31.3 & 33.2 & 7.52 & 303.8 \\
\hline Mean & 14.8 & 14.6 & 1.59 & 33.9 \\
\hline SD & 6.6 & 7.0 & 2.43 & 61.9 \\
\hline
\end{tabular}

Note: Hong Kong, Luxembourg, Malta, San Marino, Slovenia, South Korea and Taiwan were excluded because data on obesity prevalence were not available. Data on obesity prevalence for Austria came from WHO Statistics, 2010. 
Fig. 1A Subway restaurants per 100,000 people and prevalence of male obesity in advanced economies* $(n=26), 2009$.

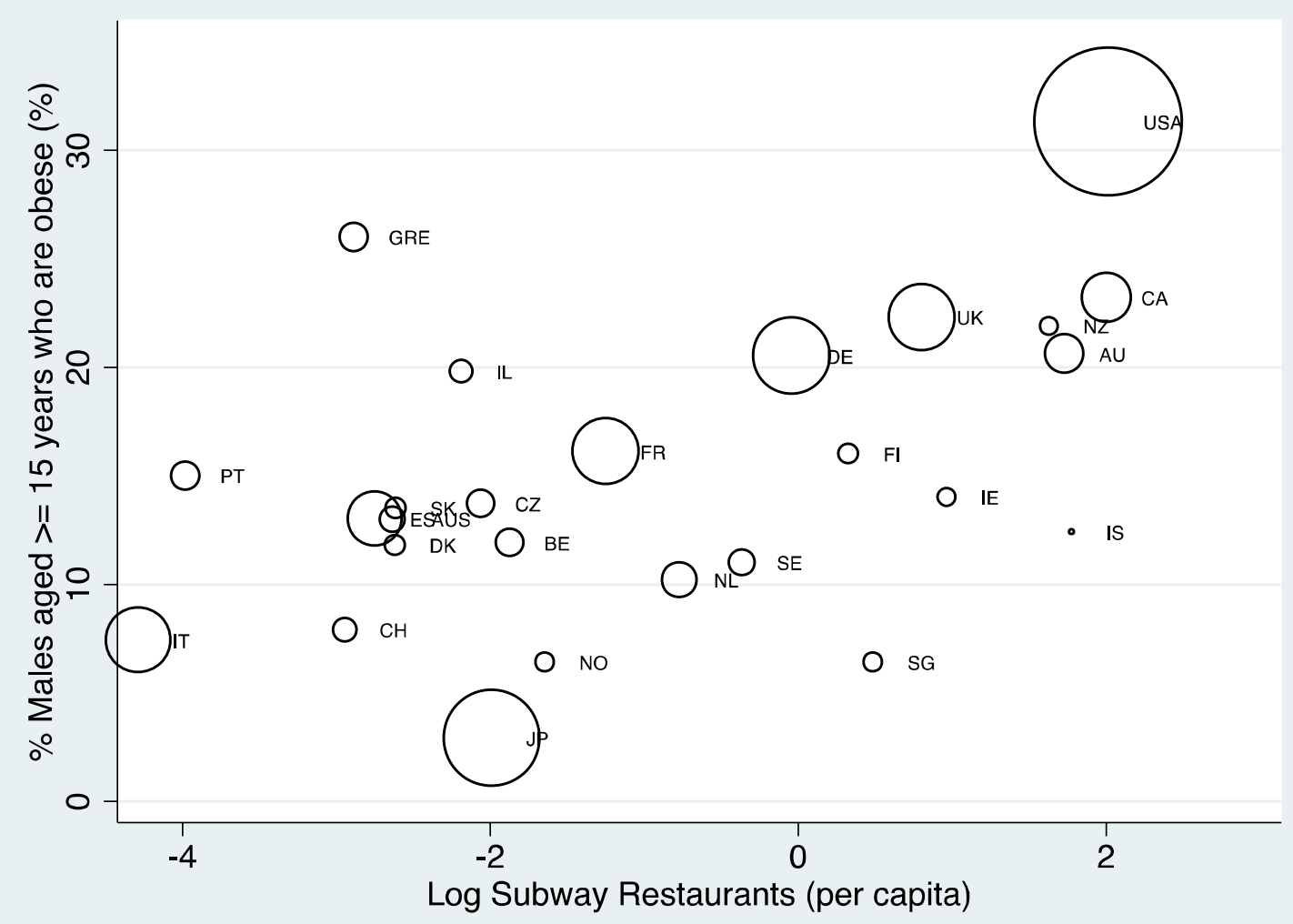

Page 8 
Fig. 1B Subway restaurants per 100,000 people and prevalence of female obesity in advanced economies $(\mathrm{n}=26), 2009$.

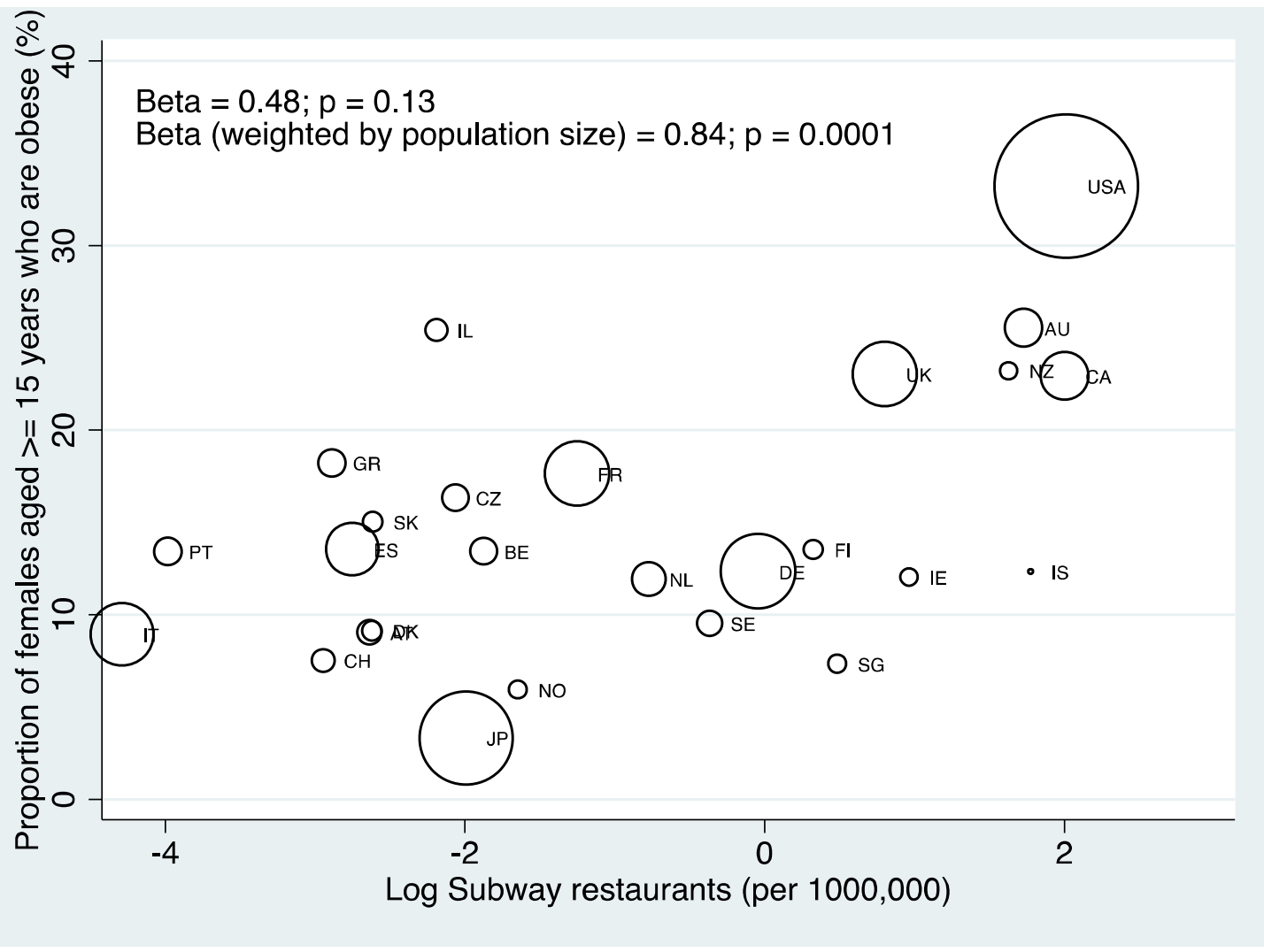

Country codes: $\mathrm{AU}=$ Australia, $\mathrm{AT}=$ Austria, $\mathrm{BE}=$ Belgium, $\mathrm{CA}=$ Canada, $\mathrm{CZ}=$ Czech Republic, $\mathrm{DK}=$ Denmark, FI = Finland, FR = France, DE = Germany, GR = Greece, IS = Iceland, IE = Ireland, IL = Israel, IT = Italy, JP = Japan, NL $=$ Netherlands, NZ = New Zealand, NO = Norway, PT $=$ Portugal, $S G=$ Singapore, $\mathrm{SK}=$ Slovakia, ES $=$ Spain, $\mathrm{SE}=$ Sweden, $\mathrm{CH}=$ Switzerland, UK = United Kingdom, USA = United States of America. 


\section{Funding:}

RDV is supported by a grant from the Economic and Social Research Council (ESRC) (RES-070-27-0034)

\section{References:}

Baum, C. 2006. An Introduction to Modern Econometrics Using STATA. College Station, TX: Stata Press.

Belsley, D. 1991. Conditioning diagnostics: collinearity and weak data in regression. New York: Wiley.

Block, J., R. Scribner, and K. DeSalvo. 2004. "Fast food, race/ethnicity and income: A geographical analysis." Am J Prev Med 27: 211-17.

Bowman, S., S. Gortmaker, C. Ebbeling, M. Pereira, and D. Ludwig. 2004. "Effects of fast food consumption on energy intake and diet quality among children in a national household study." Pediatrics 113(112-118).

Burdesse, H. and R. Whitaker. 2004. "Neighborhood playgrounds, fast food restaurants and crime: Relationships to overweight in low-income preschool children." Prev Med 38: 5763.

Business-Week. 2009. "Subway Set to Overtake McDonald's in Store Count." Business Week. Chicago, IL.

Cummins, S., L. McKay, and S. McIntyre. 2005. “McDonald's Restaurants and Neighborhood Deprivation in Scotland and England." Am J Preventive Medicine 29(4): 308-10.

Fraser, L., K. Edwards, J. Cade, and G. Clarke. 2010. "The Geography of Fast Food Outlets: A Review." Int J Environ Res Public Health 7: 2290-308.

French, S., L. Harnack, and R. Jeffrey. 2000. "Fast food restaurant use among women in the Pound of prevention study: dietary, behavioural and demographical correlates." Int J Obes 24: 1353-59.

Hawkes, C. 2009. “Uneven dietary development: linking the policies and processes of globalization with the nutrition transition, obesity and diet-related chronic diseases." Globalization and Health 2: 4.

IMF. 2009. "World Economic Outlook: Crisis and Recovery.” Washington DC: International Monetary Fund. 
Jeffrey, R., J. Baxter, M. McGuire, and J. Linde. 2006. "Are fast food restaurants an environmental risk factor for obesity?" Int J Behavioural and Physical Activity 3: 2.

Jeffrey, R. and S. French. 1998. "Epidemic obesity in the United States: Are fast foods and television viewing contributing?" Am J Public Health 88(2): 277-80.

Maddock, J. 2004 "The relationship between obesity and the prevalence of fast food restaurants: state-level analysis." Am J Health Promot 19(2): 137-43.

Offer, A., R. Pechey, and S. Ulijaszek. 2010. "Obesity under affluence varies by welfare regimes: the effect of fast food, insecurity, and inequality. ." Econ Hum Biol 8(3): 297-308.

Pearce, N. 2000. "The Ecological Fallacy Strikes Back." J Epidemiol Community Health 54: 326-27.

Prentice, A. and S. Jebb. 2003. "Fast foods, energy density and obesity: A possible mechanistic link." Obes Rev 4: 187-94.

Rabin, B., T. Boehmer, and R. Brownson. 2007. "Cross-national comparison of environmental and policy correlates of obesity in Europe." Eur J Public Health 17(1): 53-61.

Rayner, G., C. Hawkes, T. Lang, and W. Bello. 2007. "Trade liberalization and the diet transition: a public health response." Health Promotion International 21(S1): 67-73.

Reidpath, D., C. Burns, J. Garrard, M. Mahoney, and M. Townsend. 2002. "An ecological study of the relationship between social and environmental determinants of obesity." Health Place 8(2): 141-45.

Subway. "Available at www.subway.com. Accessed December 21, 2009."

Thow, A. and C. Hawkes. 2009. "The implications of trade liberalization for diet and health: a case study from Central America." Globalization and Health 5: 5.

WHO. 2009. “World Health Statistics.” Geneva: World Health Organization. Yach, D., D. Stuckler, and K. Brownell. 2006. "Epidemiologic and economic consequences of the global epidemics of obesity and diabetes." Nature Medicine 12(1): 62-66. 